\author{
Małgorzata Ostrowska ${ }^{1}$, Jerzy Bellwon ${ }^{2}$, Marek Koziński ${ }^{1}$, Adam Ostrowski ${ }^{3}$, Piotr Adamski ${ }^{1}$, \\ Piotr Niezgoda ${ }^{1}$, Krzysztof Strojek ${ }^{4}$, Marcin Gruchała² \\ 1 Department of Principles of Clinical Medicine, Collegium Medicum, Nicolaus Copernicus University, Bydgoszcz, Poland \\ $21^{\text {st }}$ Department of Cardiology, Medical University of Gdańsk, Gdańsk, Poland \\ ${ }^{3}$ Department of Urology, Collegium Medicum, Nicolaus Copernicus University, Bydgoszcz, Poland \\ ${ }^{4}$ Department of Diabetology and Nephrology, Medical University of Silesia, Katowice, Poland
}

\title{
Prevalence of electrocardiographic left ventricular hypertrophy among patients with coronary artery disease and diabetes mellitus
}

\author{
Corresponding author: \\ Małgorzata Ostrowska, MD, PhD \\ Department of Principles of Clinical \\ Medicine, \\ Collegium Medicum, \\ Nicolaus Copernicus University \\ 9 Skłodowskiej-Curie Street, \\ 85-094 Bydgoszcz, Poland \\ Phone.: + 48525854023 \\ Fax: +48525854024 \\ E-mail: ostrowska.go@gmail.com
}

Medical Research Journal 2016; Volume 1, Number 1, 1-9 10.5603/MRJ.2016.0001 Copyright @ 2016 Via Medica ISSN 2451-2591

\begin{abstract}
Introduction. Electrocardiography (ECG) is a widely used non-invasive diagnostic method for assessment of patients with cardiovascular diseases. Numerous different electrocardiographic criteria exist for detection of left ventricular hypertrophy (LVH). LVH is an important risk factor in patients with coronary artery disease (CAD) or diabetes mellitus and its presence is associated with increased cardiovascular morbidity and mortality. The aim of this study was to evaluate the prevalence of the most frequently used electrocardiographic left ventricular hypertrophy (ECG-LVH) criteria among patients with CAD and diabetes. Methods. A cross-sectional, multicenter study was conducted in outpatient clinics across Poland. Family physicians performed physical examinations and collected relevant information about: onset of CAD and diabetes, presence and onset of hypertension, dyslipidemia, heart failure, diabetic complications, history of acute coronary syndrome and pharmacotherapy. In order to detect LVH, we used seven ECG criteria: 1) the Sokolow-Lyon voltage, 2) the Gubner voltage, 3) the criterion of the R wave amplitude on the leads V5-V6 and 4) aVL, 5) the gender specific Cornell voltage and 6) product, and 7) the Romhilt-Estes point score. Centralized manual assessment of the obtained ECG tracings were performed.

Results. We enrolled 1001 patients (48.5\% women, 51.5\% men, mean age $65 \pm 11$ years) into the study. At least one ECG-LVH criterion was met in $20.0 \%(n=200)$ of the study participants. The ECG-LVH diagnosis was the most common when using the Romhilt-Estes point score ( $n=138 ; 13.8 \%)$. The corresponding prevalence rates for the Cornell voltage, the Cornell product, the $\mathrm{R}$ wave amplitude on the lead $\mathrm{aVL}$, the Sokolow-Lyon voltage, the Gubner voltage and the R wave amplitude on the leads V5-V6 criteria were $5.5 \%(n=55), 5.2 \%(n=52), 3.2 \%(n=32), 2.2 \%(n=22), 1.9 \%(n=19)$ and $1.3 \%(n=13)$ respectively. Subsequently, the prevalence of the three most frequently used in clinical practice electrocardiographic criteria for LVH (the Sokolow-Lyon voltage, the Cornell voltage and the Romhilt-Estes point score) was analyzed. At least one of them was fulfilled in 185 ECGs. All three criteria at the same time were met only in 5 ECGs (2.7\% of 185). Two and only one out of three criteria were fulfilled in 20 (10.8\%) and 160 (86.5\%) ECGs respectively.

Conclusions. The co-occurrence of all assessed ECG-LVH criteria, including the three most frequently applied in clinical practice, is very low in diabetic CAD patients. The Romhilt-Estes point score identifies the highest number of ECG-LVH cases in this setting. However, it seems reasonable to use routinely several ECG criteria for detection of LVH. Further studies are needed to compare diagnostic values of ECG-LVH criteria with imaging methods and to assess prognostic values of various ECG-LVH criteria.
\end{abstract}

Key words: electrocardiography, left ventricular hypertrophy, coronary artery disease, diabetes mellitus

Med Res J 2016; 1 (1): 1-9 


\section{Introduction}

Electrocardiography (ECG) is over 100 years old, but due to its simplicity, non-invasiveness, significant prognostic value and wide availability still remains routinely used for assessment of patients with suspected and diagnosed cardiovascular diseases. Numerous different electrocardiographic criteria exist for detection of left ventricular hypertrophy (LVH), but only several methods are used in clinical practice. Electrocardiographic evidence of $\mathrm{LVH}$ is a powerful and independent predictor of increased cardiovascular morbidity and mortality [1-6].

LVH often coexists with coronary artery disease (CAD) and diabetes mellitus. Additionally, the latter is considered a major cardiovascular risk factor associated with accelerated atherosclerosis and increased risk of micro- and macroangiopathies in subjects with and without diagnosed CAD [7-11]. As LVH progresses, myocardial oxygen demand increases, which may cause exacerbation of CAD and potentially lead to acute cardiovascular events. Interestingly, several studies have suggested that diabetes may be associated with left ventricular structural and functional abnormalities [12-14]. Diabetic patients exhibit higher left ventricle wall thickness, mass and more concentric geometry than those without diabetes. Importantly, cardiovascular morbidity and mortality increase progressively with left ventricular muscle mass [15-20].

The aim of this study was to evaluate the prevalence of the most frequently used electrocardiographic left ventricular hypertrophy (ECG-LVH) criteria among patients with $C A D$ and diabetes mellitus.

\section{Methods}

\section{Study design and conduct}

A cross-sectional, multicenter study was conducted among patients with CAD and diabetes by family physicians in primary care centers in Poland in 2009. Inclusion criteria were: 1) previous angiographically proven clinical diagnosis of CAD, 2) previous diagnosis of type 2 diabetes mellitus according to the American Diabetes Association criteria, and 3) provision of informed consent for the study participation, while exclusion criteria included: 1) the presence of ventricular pacing, 2) the presence of left or right bundle branch block, 3) the presence of left anterior or posterior hemiblock, and 4) inability of adequate ECG assessment and interpretation caused by technical reasons. For each patient, a thorough history was taken and detailed physical examination was performed. Blood pressure was measured by a physician with a mercury sphygmomanometer or an automated device in the outpatient clinic in a quiet and relaxed environment, with the subject seated for at least 10 minutes. The average of two measurements was used for the analysis. Collected information from the medical history included: history of hypertension, dyslipidemia, gout, heart failure, diabetic complications (diabetic foot, retinopathy, nephropathy and neuropathy), previous stroke and acute coronary syndrome as well as duration of hypertension, diabetes and CAD. Hypertension was defined as systolic blood pressure $\geq 140 \mathrm{~mm} \mathrm{Hg}$ and/or diastolic blood pressure $\geq 90 \mathrm{~mm} \mathrm{Hg}$ or treatment with anti-hypertensive drugs. Measured laboratory parameters included: fasting plasma glucose, glycated hemoglobin $\left(\mathrm{HbA}_{1 \mathrm{c}}\right)$, total cholesterol, high-density lipoprotein (HDL) cholesterol, low-density lipoprotein (LDL) cholesterol and triglycerides. The aforementioned results were taken from patient documentation when measured within 12 months. Detailed information on participants' pharmacological treatment during the last 6 months was recorded, including the use of metformin, sulfonylurea derivatives, insulin, acetylsalicylic acid, clopidogrel, statins, fibrates, angiotensin-converting enzyme inhibitors, angiotensin II receptor blockers, beta-adrenolytics, diuretics and calcium channel antagonists.

The study protocol was approved by the Local Ethics Committee in accordance with the Declaration of Helsinki.

\section{Electrocardiography}

Standard supine 12-lead electrocardiograms were registered at a $25 \mathrm{~mm} / \mathrm{s}$ speed and $10 \mathrm{~mm} / \mathrm{mV}$ gain. ECGs were read according to the AHA/ACCF/HRS Recommendations for the Standardization and Interpretation of the Electrocardiogram [21]. Centralized measurements were performed in all ECGs manually, questionable cases were resolved by consensus of experienced cardiologists. In order to detect LVH, we used seven methods, including various voltage criteria and point score system. Electrocardiographic criteria for the LVH diagnosis were as follows: 1) the Sokolow-Lyon voltage - sum of the S wave in lead V1 and the largest $\mathrm{R}$ wave in the lead $\mathrm{V} 5$ or $\mathrm{V} 6 \geq 3.5 \mathrm{mV}$ [22], 2) the criterion of the $R$ wave amplitude in the lead $V 5$ or $\mathrm{V} 6 \geq 2.6 \mathrm{mV}$ [22], 3) the criterion of the $\mathrm{R}$ wave amplitude in the lead $\mathrm{aVL} \geq 1.1 \mathrm{mV}$ [23], 4) the Gubner voltage - sum of the $R$ wave in the lead $I$ and the $S$ wave in the lead III $\geq 2.5 \mathrm{mV}$ [24], 5) the gender specific Cornell voltage - sum of the $R$ wave in the lead $a V L$ and the $S$ wave in the lead $\mathrm{V} 3 \geq 2.0 \mathrm{mV}$ in women and $\geq 2.8 \mathrm{mV}$ in men [25], 6) the gender specific Cornell product — sum of the $R$ wave in the lead $a V L$ and the $S$ wave in the lead V3 (for women, added $8 \mathrm{~mm}$ ), all multiplied by the mean QRS interval, result $\geq 2436 \mathrm{~mm}$ was considered positive for LVH [26], and 7) the Romhilt and Estes point score [27]. The latter comprises amplitudes of 
the $\mathrm{R}$ or $\mathrm{S}$ waves $>20 \mathrm{~mm}$ in the limb leads (1 point) or $>30 \mathrm{~mm}$ in precordial leads (1 point), ST-T segment strain pattern in V5 or V6 (3 points, but when using digitalis - it is only 1 point), the $P$ wave amplitude $>1 \mathrm{~mm}$ and duration $>40 \mathrm{~ms}$ in the lead V1 (3 points), QRS electrical axis $>-30$ degrees (2 points); QRS duration $>90 \mathrm{~ms}$ in the lead V6 (1 point) and initial time of the intrinsicoid deflection of the QRS $>50 \mathrm{~ms}$ in V5 or V6 (1 point). In the Romhilt-Estes point score, LVH is diagnosed when the score is $\geq 5$ points.

We prespecified an additional analysis including the three most frequently applied in clinical practice ECG criteria for detection of LVH - the Sokolow-Lyon voltage, the Cornell voltage and the Romhilt-Estes point score.

\section{Statistical analysis}

Results are shown as mean \pm standard deviation (SD) for continuous variables and as number and percent for categorical variables. Continuous data were checked for normal distribution by means of Shapiro-Wilk W test. Differences in clinical characteristics between patients with and without ECG-LVH were assessed using the Chi-square test for categorical variables and the Student's t-test for normally distributed continuous variables. The non-parametric Mann-Whitney $U$ test and the ANOVA Kruskal-Wallis test were applied for comparisons of continuous variables whose distribution deviated from normality. Spearman's rank correlation coefficient was used to determine strength of relationship between tested variables. A two-sided difference was considered significant at $p<0.05$. The statistical analysis was carried out using the Statistica 9.1 package (StatSoft, Tulsa, OK, USA).

\section{Results}

Out of 1116 potentially eligible patients, 1001 subjects (485 women and 516 men) were enrolled into the study. We excluded 115 participants due to: paced rhythm in the assessed ECG ( $n=18$ cases), the presence of left or right bundle branch block $(n=76)$ or inability of adequate ECG assessment and interpretation caused by technical reasons $(n=21)$. The clinical characteristic of the study population is reported in Table 1.

There were 200 patients $(20.0 \%)$ who met at least one ECG criteria for $\mathrm{LVH}$. In details, we found electrocardiographic evidence of LVH fulfilling at least 1 criterion in 99 women (20.4\%) and in 101 men (19.6\%). The prevalence of $\mathrm{LVH}$ varied widely due to the criteria used. There was no patient fulfilling all seven LVH criteria. The prevalence of $\mathrm{LVH}$ was the highest when using the
Romhilt-Estes point score (13.8\%) and the lowest when using the criterion of the $\mathrm{R}$ wave amplitude in the lead V5 or V6 (1.3\%) (Tab. 2).

At least one of the three most frequently used criteria, the Sokolow-Lyon voltage, the Cornell voltage and the Romhilt-Estes point score, was met in 185 patients (18.5\% of all 1001 patients), while all three criteria at the same time were fulfilled only in 5 patients $(2.7 \%$ of 185 patients with at least one of the three above listed criteria). Two out of the three above mentioned criteria at the same time were met in 20 patients (10.8\%): the Sokolow-Lyon voltage and the Cornell voltage in 3 patients (1.6\%), the Sokolow-Lyon voltage and the Romhilt-Estes point score in 6 patients (3.2\%) and the Cornell voltage and the Romhilt-Estes point score in 11 patients $(6.0 \%)$. Only one criterion was met in the large majority of patients - $160(86.5 \%)$ : the Sokolow-Lyon voltage in 8 patients $(4.3 \%)$, the Cornell voltage in 36 patients $(19.5 \%)$ and the Romhilt-Estes point score in 116 patients (62.7\%) (Fig. 1).

Differences in clinical characteristics among patients meeting commonly used ECG criteria for LVH (the Sokolow-Lyon voltage, the Cornell voltage and the Romhilt-Estes point score) are presented in Table 3.

We found a trend showing positive correlation between duration of hypertension and magnitude of the Sokolow-Lyon voltage criterion $(r=0.38, p=0.095)$ but no correlation with either systolic or diastolic blood pressure. There were no correlations between either blood pressure levels or duration of hypertension and magnitude of the Cornell voltage criterion.

\section{Discussion}

Large amount of research evidence indicates that sensitivity of traditional electrocardiographic criteria for $\mathrm{LVH}$ is relatively poor when compared with the reference standard for LVH assessment - echocardiography [28-34]. However, Verdecchia et al. and Schillaci et al. suggest that using the combination of three highly specific criteria: the Romhilt-Estes point score, left ventricular strain and Cornell criteria in a cumulative score can produce a rise in sensitivity without excessive deterioration of specificity [35, 36]. Importantly, even single electrocardiographic criteria for LVH are highly specific, with specificity exceeding $90 \%$ [37].

In a population of patients with CAD and concomitant diabetes, we found that the prevalence of LVH detected by ECG was $20 \%$ and ranged widely from $1 \%$ to $14 \%$, depending on the criterion used. The LIFE study demonstrated that diabetes is associated with an increased prevalence and severity of ECG-LVH assessed according to the Cornell criteria [38]. In contrast, in high- 


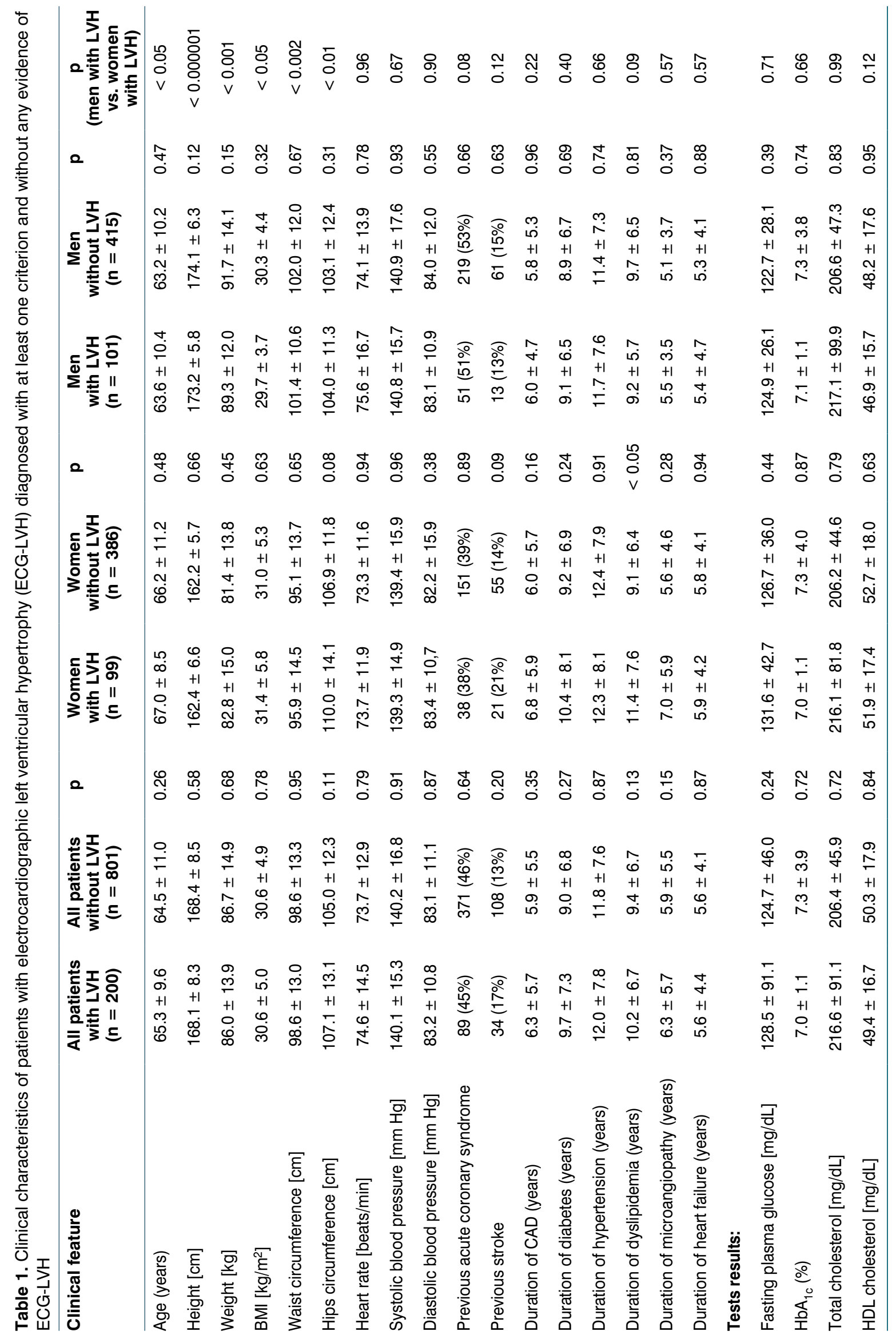




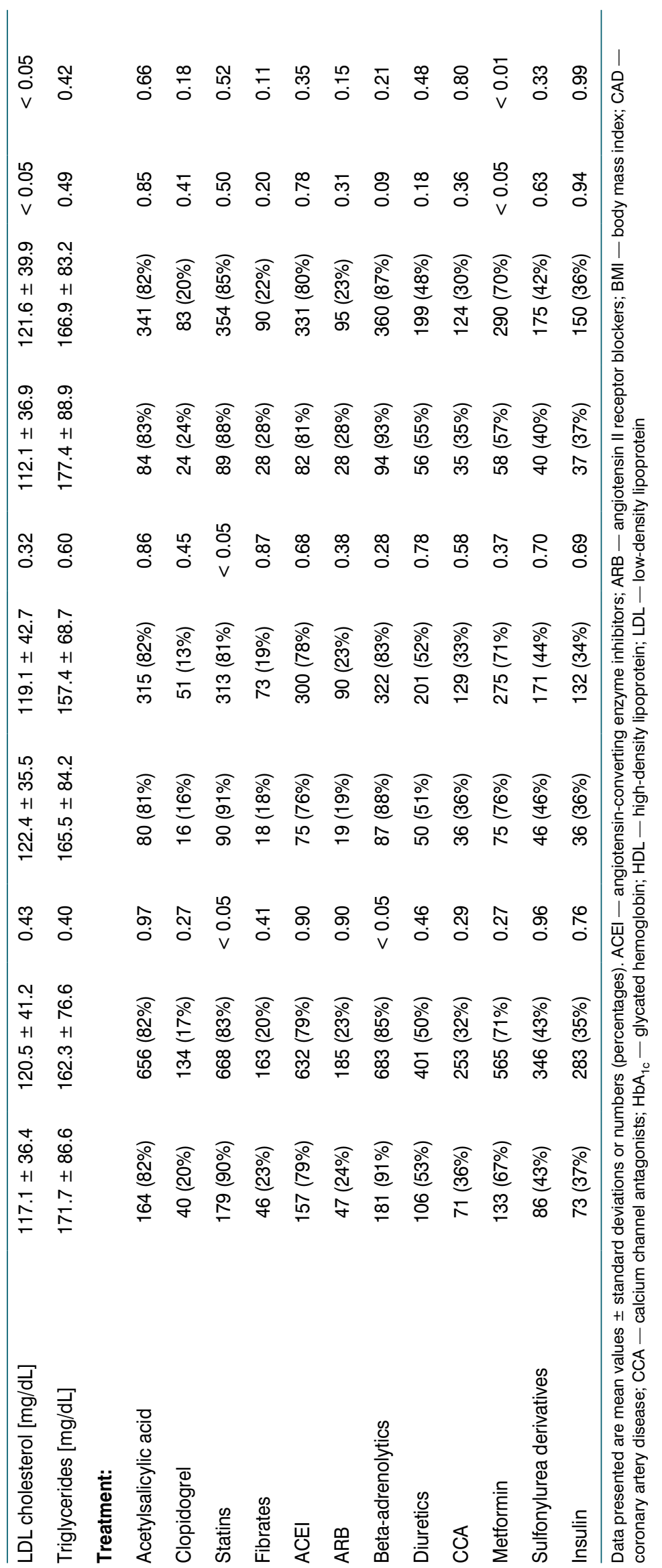


Table 2. Prevalence of left ventricular hypertrophy based on seven assessed electrocardiographic criteria

\begin{tabular}{lccc}
\hline Criterion & $\begin{array}{c}\text { All analyzed patients } \\
\mathbf{( n = 1 0 0 1 )} \\
\mathbf{n}(\%)\end{array}$ & $\begin{array}{c}\text { Men } \\
(\mathbf{n = 5 1 6 )} \\
\mathbf{n ~ ( \% )}\end{array}$ & $\begin{array}{c}\text { Women } \\
(\mathbf{n}=\mathbf{4 8 5}) \\
\mathbf{n}(\%)\end{array}$ \\
\hline The R wave amplitude on the lead V5 or V6 criterion & $13(1.3)$ & $8(1.6)$ & $5(1.0)$ \\
The Gubner voltage criterion & $19(1.9)$ & $10(1.9)$ & $9(1.9)$ \\
The Sokolow-Lyon voltage criterion & $22(2.2)$ & $14(2.7)$ & $8(1.6)$ \\
The R wave amplitude on the lead aVL criterion & $32(3.2)$ & $17(3.3)$ & $15(3.1)$ \\
The Cornell product criterion & $52(5.2)$ & $24(4.7)$ & $28(5.8)$ \\
The Cornell voltage criterion & $55(5.5)$ & $18(3.5)$ & $37(7.6)$ \\
The Romhilt-Estes point score & $138(13.8)$ & $78(15.1)$ & $60(12.4)$ \\
\hline
\end{tabular}

-risk patients in the HOPE study, there was no difference in the prevalence of diabetes between patients with and without ECG-LVH determined using the Sokolow-Lyon criterion [39]. In our population of diabetic patients with $\mathrm{CAD}$, the prevalence of the Cornell voltage criterion was about $6 \%$, while the prevalence of the Sokolow-Lyon voltage criterion was only $2 \%$.

Bruno et al. investigated ECGs of 965 patients with type 2 diabetes mellitus and assessed the prevalence of ECG-LVH and its relationship with clinical and metabolic variables [40]. Patients with ECG-LVH were older than those without it, but there were no further differences in terms of body mass index, duration of diabetes, diabetes treatment, systolic and diastolic blood pressure, presence of CAD or hypertension. Interestingly, the comparison of patients with and without ECG-LVH in our study revealed that the former subjects were more often treated with beta-adrenolytics and statins.

According to our observations, it seems insufficient to use only one ECG criterion for detection of LVH in patients with CAD and DM, because each criterion identifies a different group of patients. In our study, $86.5 \%$ of subjects met only one out of the three most frequently used electrocardiographic criteria. It suggests the criteria are complementary and should be used in combination in order to detect ECG-LVH. González-Juanatey et al. indicated that the Cornell and Sokolow-Lyon diagnostic criteria enable us to identify hypertensive patients with LVH with different epidemiologic and cardiovascular risk profiles [41]. In men, LVH was preferably diagnosed using the Sokolow-Lyon criterion, whereas women more frequently fulfilled the Cornell criterion. In our study, the Sokolow-Lyon criterion was fulfilled in $2.7 \%$ of men and in $1.6 \%$ of women, while the Cornell criterion was met in $3.5 \%$ of men and in $7.6 \%$ of women.

The severity of ECG-LVH may be assessed by determining the magnitude of the voltage criteria. González-Juanatey et al. found positive correlations

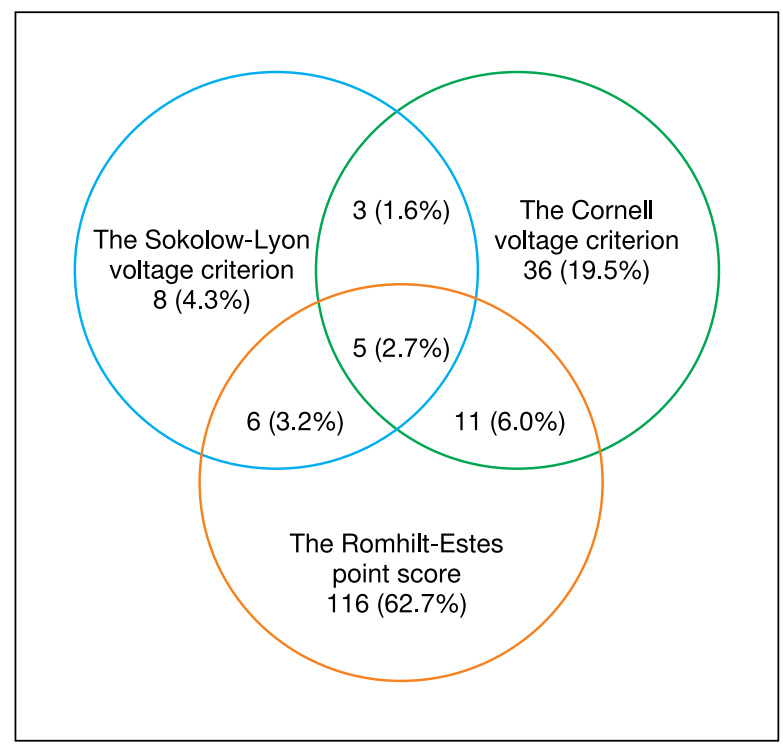

Figure 1. Coexistence of the three most frequently used ECG-LVH criteria; ECG-LVH - electrocardiographic left ventricular hypertrophy. Percentages are calculated out of all patients who fulfilled at least one of the three assessed ECG-LVH criteria $(n=185)$

between systolic and diastolic blood pressure levels and severity of both the Sokolow-Lyon and the Cornell voltage criteria [41]. We also analyzed the severity of ECG-LVH reflected by the magnitude of the Sokolow-Lyon and the Cornell voltage criteria. In our study, there was a trend showing that the severity of LVH due to the Sokolow-Lyon criterion positively correlated with the duration of hypertension. However, we failed to find any correlations between the severity of the Cornell voltage and blood pressure levels or duration of hypertension. Importantly, a large majority of our study participants were treated with antihypertensive drugs.

There are some limitations of the study that deserve attention. First of all, ECGs were recorded in our study using analog, but not digital, systems and therefore 
Table 3. Clinical characteristics of patients meeting the three most frequently used electrocardiographic criteria of left ventricular hypertrophy

\begin{tabular}{|c|c|c|c|c|}
\hline Clinical feature & $\begin{array}{l}\text { The Sokolow-Lyon } \\
\text { criterion } \\
(n=8)\end{array}$ & $\begin{array}{c}\text { The Cornell } \\
\text { voltage criterion } \\
(n=36)\end{array}$ & $\begin{array}{c}\text { The Romhilt-Estes } \\
\text { point score } \\
(n=116)\end{array}$ & $\mathbf{p}$ \\
\hline Age (years) & $68.1 \pm 6.3$ & $65.6 \pm 9.3$ & $65.0 \pm 9.6$ & 0.54 \\
\hline Height $[\mathrm{cm}]$ & $169.5 \pm 8.1$ & $166.4 \pm 6.8$ & $167.7 \pm 8.8$ & 0.53 \\
\hline Weight [kg] & $81.4 \pm 15.2$ & $86.7 \pm 18.3$ & $85.1 \pm 12.1$ & 0.62 \\
\hline BMI $\left[\mathrm{kg} / \mathrm{m}^{2}\right]$ & $28.3 \pm 4.7$ & $31.3 \pm 6.8$ & $30.3 \pm 4.1$ & 0.39 \\
\hline Waist circumference [cm] & $96.1 \pm 11.4$ & $100.1 \pm 16.0$ & $98.2 \pm 12.6$ & 0.61 \\
\hline Hips circumference [cm] & $106.0 \pm 10.7$ & $110.0 \pm 14.8$ & $106.3 \pm 12.9$ & 0.53 \\
\hline Heart rate [beats/min] & $65.5 \pm 13.9$ & $75.5 \pm 13.1$ & $74.4 \pm 14.5$ & 0.08 \\
\hline Systolic blood pressure [mm Hg] & $146.6 \pm 15.1$ & $142.0 \pm 15.1$ & $138.2 \pm 14.2$ & 0.11 \\
\hline Diastolic blood pressure [mm Hg] & $86.1 \pm 10.6$ & $83.3 \pm 8.6$ & $82.6 \pm 11.0$ & 0.70 \\
\hline Duration of CAD (years) & $2.6 \pm 2.8$ & $7.8 \pm 5.4$ & $6.2 \pm 6.2$ & $<0.05$ \\
\hline Duration of diabetes (years) & $8.4 \pm 5.8$ & $13.7 \pm 9.2$ & $8.5 \pm 6.6$ & $<0.01$ \\
\hline Duration of hypertension (years) & $14.9 \pm 9.1$ & $14.9 \pm 10.1$ & $10.8 \pm 7.0$ & 0.06 \\
\hline Duration of dyslipidemia (years) & $9.6 \pm 5.6$ & $13.4 \pm 7.7$ & $9.3 \pm 6.7$ & 0.09 \\
\hline Duration of microangiopathy (years) & $1.5 \pm 1.0$ & $6.6 \pm 4.3$ & $7.0 \pm 6.0$ & $<0.05$ \\
\hline Duration of heart failure (years) & $4.8 \pm 4.3$ & $7.8 \pm 6.1$ & $5.3 \pm 4.1$ & 0.49 \\
\hline Duration of ACEI treatment (years) & $6.8 \pm 2.6$ & $9.2 \pm 5.3$ & $7.8 \pm 4.4$ & 0.33 \\
\hline Fasting plasma glucose [mg/dL] & $114.2 \pm 16.0$ & $135.6 \pm 44.9$ & $127.3 \pm 31.2$ & 0.62 \\
\hline $\mathrm{HbA}_{1 \mathrm{c}}(\%)$ & $6.0 \pm 0.0$ & $7.1 \pm 1.2$ & $7.1 \pm 1.1$ & 0.51 \\
\hline Total cholesterol [mg/dL] & $206.3 \pm 24.6$ & $210.2 \pm 61.3$ & $213.6 \pm 100.0$ & 0.83 \\
\hline HDL cholesterol [mg/dL] & $39.8 \pm 7.5$ & $52.7 \pm 14.2$ & $48.9 \pm 18.4$ & 0.07 \\
\hline LDL cholesterol [mg/dL] & $97.3 \pm 25.3$ & $122.8 \pm 40.2$ & $115.2 \pm 33.4$ & 0.34 \\
\hline Triglycerides [mg/dL] & $137.0 \pm 11.0$ & $152.0 \pm 61.8$ & $174.9 \pm 95.2$ & 0.40 \\
\hline \multicolumn{5}{|l|}{ Treatment: } \\
\hline Acetylsalicylic acid & $8(100 \%)$ & $28(78 \%)$ & $93(80 \%)$ & 0.14 \\
\hline Clopidogrel & $2(25 \%)$ & $5(14 \%)$ & $25(22 \%)$ & 0.44 \\
\hline Statins & $8(100 \%)$ & $35(97 \%)$ & 103 (89\%) & 0.63 \\
\hline Fibrates & $2(25 \%)$ & $4(11 \%)$ & $28(24 \%)$ & 0.30 \\
\hline ACEI & $4(50 \%)$ & $30(83 \%)$ & $94(81 \%)$ & $<0.05$ \\
\hline ARB & $4(50 \%)$ & $6(17 \%)$ & $23(20 \%)$ & $<0.05$ \\
\hline Beta-adrenolytics & $8(100 \%)$ & 33 (92\%) & $103(89 \%)$ & 0.40 \\
\hline Diuretics & $4(50 \%)$ & $19(53 \%)$ & $62(53 \%)$ & 0.89 \\
\hline CCA & $3(38 \%)$ & $9(25 \%)$ & $39(34 \%)$ & 0.47 \\
\hline Metformin & $6(75 \%)$ & $27(75 \%)$ & $69(59 \%)$ & 1.00 \\
\hline Sulfonylurea derivatives & $3(38 \%)$ & $11(31 \%)$ & $58(50 \%)$ & 0.70 \\
\hline Insulin & $2(25 \%)$ & $15(42 \%)$ & $37(32 \%)$ & 0.38 \\
\hline \multicolumn{5}{|l|}{ Previous incidents: } \\
\hline Previous acute coronary syndrome & $3(38 \%)$ & $15(42 \%)$ & $50(43 \%)$ & 0.83 \\
\hline Previous stroke & $1(13 \%)$ & $8(22 \%)$ & $19(16 \%)$ & 0.54 \\
\hline
\end{tabular}

Data are presented as mean values \pm SD or numbers (percentages). ACEI - angiotensin-converting enzyme inhibitors; ARB - angiotensin II receptor blockers; $\mathrm{BMI}$ - body mass index; CAD — coronary artery disease; CCA — calcium channel antagonists; $\mathrm{HbA}_{1 \mathrm{c}}$ - glycated hemoglobin; HDL — high-density lipoprotein; LDL — low-density lipoprotein 
they were analyzed manually. Secondly, we were not able to use the same electrocardiographic devices for all patients in different regions of Poland. Thirdly, some subgroup analyses in our study were underpowered. Fourthly, we did not assess left ventricular mass or wall thickness by echocardiography or magnetic resonance imaging and therefore we could not calculate the specificity or sensitivity of the compared ECG-LVH criteria. Finally, further studies are needed to verify the prognostic values of various ECG-LVH criteria.

\section{Conclusions}

The co-occurrence of all assessed ECG-LVH criteria, including the three most frequently applied in clinical practice, is very low in diabetic CAD patients. The Romhilt-Estes point score identifies the highest number of ECG-LVH cases in this setting. However, it seems reasonable to use routinely several ECG criteria for detection of $\mathrm{LVH}$. Further studies are needed to compare diagnostic values of ECG-LVH criteria with imaging methods and to assess prognostic values of various ECG-LVH criteria.

\section{Acknowledgements}

The authors are very grateful to all doctors and medical students engaged in the analysis of the electrocardiograms.

\section{References}

1. Larstorp AC, Okin PM, Devereux RB et al. Changes in electrocardiographic left ventricular hypertrophy and risk of major cardiovascular events in isolated systolic hypertension: the LIFE study. J Hum Hypertens 2011; 25: 178-185.

2. Verdecchia P, Schillaci G, Borgioni $C$ et al. Prognostic value of a new electrocardiographic method for diagnosis of left ventricular hypertrophy. J Am Coll Cardiol 1998; 31: 383-390.

3. Levy D, Salomon M, D'Agostino RB, Belanger AJ, Kannel WB. Prog nostic implications of baseline electrocardiographic features and their serial changes in subjects with left ventricular hypertrophy. Circulation 1994; 90: 1786-1793.

4. Mathew J, Sleight P, Lonn E et al. Reduction of cardiovascular risk by regression of electrocardiographic markers of left ventricular hypertrophy by the angiotensin-converting enzyme inhibitor ramipril. Circulation 2001; 104: 1615-1621.

5. Havranek EP, Esler A, Estacio RO, Mehler PS, Schrier RW. Differentia effects of antihypertensive agents on electrocardiographic voltage: results from the Appropriate Blood Pressure Control in Diabetes (ABCD) trial. Am Heart J 2003; 145: 993-998.

6. Okin PM, Devereux RB, Jern S et al. for the LIFE Study Investigators. Regression of electrocardiographic left ventricular hypertrophy during antihypertensive treatment and prediction of major cardiovascular events. JAMA 2004; 292: 2343-2349.

7. Kannel WB, McGee DL. Diabetes and cardiovascular risk factors: the Framingham Study. Circulation 1979; 59: 8-13.

8. Kannel WB, McGee DL. Diabetes and cardiovascular disease: the Framingham Heart Study. JAMA 1979; 241: 2034-2038.

9. Kleinmann JC, Donahue RP, Harris MI, Finacune FF, Madans JH, Brock DB. Mortality among diabetics in a national sample. Am J Epidemiol 1988; 128: 389-401.
10. Howard BV, Lee ET, Cowan LD et al. Rising tide of cardiovascular disease in American Indians: the Strong Heart Study. Circulation 1999; 99: 2389-2395.

11. Howard BV, Rodriguez BL, Bennett PH et al. Prevention Conference VI: diabetes and cardiovascular disease: Writing Group I: epidemiology. Circulation 2002; 105: 132-137.

12. Ashmed SS, Jaferi GA, Narang GM et al. Preclinical abnormality of left ventricular function in diabetes mellitus. Am Heart J 1975; 89: 153-158.

13. Grossman E, Shemesh J, Shamiss A, et al. Left ventricular mass in diabetes-hypertension. Arch Intern Med 1992; 152: 1001-1004.

14. Palmieri V, Bella JN, Arnett DK et al. Effect of Type 2 Diabetes Mellitus on Left Ventricular Geometry and Systolic Function in Hypertensive Subjects: Hypertension Genetic Epidemiology Network (HyperGEN) Study. Circulation 2001; 103: 102-107.

15. Kannel WB, Gordon T, Casetelli WP, Margolis JR. Electrocardiographic left ventricle hypertrophy and risk of coronary heart disease. The Framingham Study. Ann Intern Med 1970; 72: 813-822.

16. Kannel WB, Cobb J. Left ventricular hypertrophy and mortality — results from the Framingham Study. Cardiology 1992; 81: 291-298.

17. Sullivan JM, Vander Zwaag RV, el-Zeky F, Ramanathan KB, Mirvis DM. Left ventricular hypertrophy: effects on survival. J Am Coll Cardiol 1993; 22: 508-513.

18. Casale PN, Devereux RB, Milner M et al. Value of echocardiographic measurement of left ventricular mass in predicting cardiovascular morbid events in hypertensive men. Ann Intern Med 1986; 105: 173-178.

19. Koren MJ, Devereux RB, Casale PN, Savage DD, Laragh JH. Relation of left ventricular mass and geometry to morbidity and mortality in men and women with uncomplicated essential hypertension. Ann Intern Med 1991; 114: 345-352.

20. Levy D, Garrison RJ, Savage DD, Kannel WB, Castelli WP. Prognostic implications of echocardiographically determined left ventricular mass in the Framingham Heart Study. N Eng J Med 1990; 322: 1561-1566.

21. Hanock EW, Deal BJ, Mirvis DM et al. AHA/ACCF/HRS Recommendations for the Standardization and Interpretation of the Electrocardiogram: Part V: Electrocardiogram Changes Associated With Cardiac Chamber Hypertrophy A Scientific Statement From the American Heart Association Electrocardiography and Arrhytmiaas Committee, Council of Clonical Cardiology; The American College of Cardiology Foundation; and the Heart Rhythm Society Endorsed by the International Society for the Computerized Electrocardiology. J Am Coll Cardiol 2009; 53: 992-1002.

22. Sokolow M, Lyon TP. The ventricular complex in left ventricular hypertrophy as obtained by unipolar precordial and limb leads. Am Heart $J$ 1949; 37: 161-186.

23. Levy D, Labib SB, Anderson KM, Christiansen JC, Kannel WB, Castelli WP. Determinants of sensitivity and specificity of electrocardiographic criteria for left ventricular hypertrophy. Circulation 1990; 81: 815-820.

24. Gubner R, Ungerleider HE. Electrocardiographic criteria of left ventricular hypertrophy. Arch Intern Med 1943; 72: 196-206

25. Casale P, Devereux R, Kligfield P et al. Electrocardiographic detection of left ventricular hypertrophy: development and prospective validation of improved criteria. J Am Coll Cardiol 1985; 6: 572-580.

26. Molloy T, Okin P, Devereux R, Kligfield P. Electrocardiographic detection of left ventricular hypertrophy by the simple QRS voltage-duration product. J Am Coll Cardiol 1992; 20: 1180-1186.

27. Romhilt D, Estes E. Point-score system for the ECG diagnosis of left ventricular hypertrophy. Am Heart J 1968; 75: 752-758.

28. Casiglia E, Schiavon L, Tikhonoff $\mathrm{V}$, et al. Electrocardiographic criteria of left ventricular hypertrophy in general population. Eur $\mathrm{J}$ Epidemiol 2008; 23: 261-271.

29. Gopal AS, Butkevich A, Roychoudhury D, Phillips RA. Evaluation of the electrocardiographic criteria for left ventricular hypertrophy with use of three-dimensional echocardiography. Echocardiography 2006; 23: 756-762.

30. Okin PM, Wright JT, Nieminen MS, et al. Ethnic differences in electrocardiographic criteria for left ventricular hypertrophy: the LIFE study. Losartan Intervention For Endpoint. Am J Hypertens 2002; 15: 663-671.

31. Gasperin CA, Germiniani H, Facin CR, Souza AM, Cunha CL. An analysis of electrocardiographic criteria for determining left ventricular hypertrophy. Arq Bras Cardiol 2002; 78: 59-82.

32. Norman JE Jr, Levy D. Improved electrocardiographic detection of echocardiographic left ventricular hypertrophy: results of a correlated data base approach. J Am Coll Cardiol 1995; 26: 1022-1029.

33. Vijan SG, Manning G, Millar-Craig MW. How reliable is the electrocardiogram in detecting left ventricular hypertrophy in hypertension? Postgrad Med J 1991; 67: 646-648.

34. Levy D, Labib SB, Anderson KM, Christiansen JC, Kannel WB, Castelli WP. Determinants of sensitivity and specificity of electrocardiographic criteria for left ventricular hypertrophy. Circulation 1990; 81: 815-820. 
35. Verdecchia P, Dovellini EV, Gorini M et al. Comparison of electrocardiographic criteria for diagnosis of left ventricular hypertrophy in hypertension: the MAVI study. Ital Heart J 2000; 1: 207-215.

36. Schillaci G, Verdecchia P, Borgioni $C$ et al. Improved electrocardiographic diagnosis of left ventricular hypertrophy. Am J Cardiol 1994; 74: 714-719

37. Devereux RB, Casale PN, Eisenberg RR, Miller DH, Kligfield P. Electrocardiographic detection of left ventricular hypertrophy using echocardiographic determination of left ventricular mass as the reference standard. Comparison of standard criteria, computer diagnosis and physician interpretation. J Am Coll Cardiol 1984; 3: 82-87.

38. Okin PM, Devereux RB, Gerdts E et al. Impact of diabetes mellitus on regression of electrocardiographic left ventricular hypertrophy and the prediction of outcome during antihypertensive therapy. The Losartan Intervention For Endpoint (LIFE) Reduction in Hypertension Study. Circulation 2006; 113: 1588-1596.

39. Lonn E, Mathew J, Pogue J et al. Heart Outcomes Prevention Evaluation Study Investigators. Relationship of electrocardiographic left ventricular hypertrophy to mortality and cardiovascular morbidity in high-risk patients. Eur J Cardiovasc Prevention Rehabil 2003; 10: 420-428.

40. Bruno G, Giunti S, Bargero G, Ferrero S, Pagano G, Perin PC. Sex differences in prevalence of electrocardiographic left ventricular hypertrophy in type 2 diabetes: The Casale Monferrato Study. Diabet Med 2004; 21: 823-828.

41. González-Juanatey JR, Cea-Calvo L, Bertomeu V, Aznar J. Electrocardiographic Criteria for Left Ventricular Hypertrophy and Cardiovascular Risk in Hypertensives. VIIDA Study. Rev Esp Cardiol 2007; 60: 148-156. 